\title{
Effect of vascular endothelial growth factor siRNA and wild-type p53 co-expressing plasmid in MDA-MB-231 cells
}

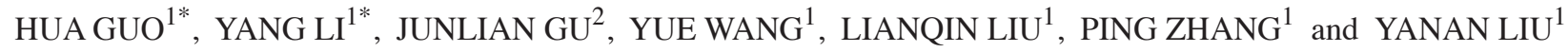 \\ ${ }^{1}$ Department of Pathophysiology, Prostate Diseases Prevention and Treatment Research Center, \\ Norman Bethune College of Medicine, Jilin University, Changchun, Jilin 130021; ${ }^{2}$ Department of Pathology, \\ Shandong Provincial Qianfoshan Hospital, Shandong University, Jinan, Shandong 250013, P.R. China
}

Received February 1, 2015; Accepted September 22, 2015

DOI: $10.3892 / \mathrm{mmr} .2015 .4571$

\begin{abstract}
Breast cancer urgently requires improved therapeutic strategies. In the current study, a Pvp53 plasmid that co-expressed p53 and short-interfering RNA against vascular endothelial growth factor (si-VEGF) was developed to replace single plasmid transfections. Whether Pvp53 exhibited improved anti-tumor effects in breast cancer MDA-MB-231 cells was investigated in the present study. Pvp53 significantly reduced the $\mathrm{Bcl}-2 / \mathrm{Bax}$ ratio and increased the expression of cleaved caspase-3 and 8. Compared with p53 and si-VEGF single transfections, the Pvp53 co-expression plasmid significantly increased the proportion of apoptotic cells and inhibited cell motility and proliferation. These results indicated that the Pvp53 co-expression plasmid has greater inhibitory effects on breast cancer MDA-MB-231 cells than single plasmids.
\end{abstract}

\section{Introduction}

Breast cancer is the predominant malignant tumor amongst women (1). Although China has a low incidence of breast cancer compared with Europe and North America, incidence has increased in recent years whilst the age of onset has reduced (2). The World Health Organization notes breast cancer as a serious threat to women's health (3). Breast cancer metastasis is a key factor that affects the prognosis and clinical outcomes for patients, therefore effective control of tumor invasion and metastasis is critical to improve the prognosis for patients with breast cancer. Multiple studies (4-6) have demonstrated that the occurrence and development of breast cancer involves the inactivation of tumor suppressor genes and mutations in oncogenes.

Correspondence to: Ms Yanan Liu, Department of Pathophysiology, Prostate Diseases Prevention and Treatment Research Center, Norman Bethune College of Medicine, Jilin University, 126 Xinmin Street, Changchun, Jilin 130021, P.R. China

E-mail:ynliu@jlu.edu.cn

*Contributed equally

Key words: p53, vascular endothelial factor, co-expression, breast cancer, apoptosis
Furthermore, aberrant regulation of cellular apoptosis serves an important role in carcinogenesis (7).

For tumors to develop, an adequate supply of nutrients and oxygen is required (8). However, as the tumors continue to grow, nutrient and oxygen consumption requirements increase, while the supply begins to decline. At this point, the tumor requires new blood vessels to maintain its growth. Vascular endothelial growth factor (VEGF) is the most important factor in vascular regulation (9). In tumor development, hypoxia activates hypoxia inducible factor $1 \alpha$ $(\mathrm{HIF}-1 \alpha)$ and VEGF to induce neovascularization (10). VEGF is required for the regeneration of blood vessels in embryos and in adults following injury (11). High expression levels of VEGF have been demonstrated to be negatively correlated with the patient survival rate in a variety of solid tumors $(12,13)$.

p53 is the most frequent tumor suppressor gene mutated in human cancers (14). However, in approximately 50-60\% of the tumors harboring p53 mutations, recovery of wild-type p53 expression suppresses tumor growth and metastasis (15). A previous study demonstrated that during hypoxia, p53 has a dual-directional regulatory function for VEGF. In the early stages of hypoxia, p53 and HIF-1 $\alpha$ interactions promote the expression of VEGF, however, during long-term hypoxia, p53 exerts an inhibitory effect on VEGF (16). Agani et al (17) observed that in Hep3B human hepatoblastoma and RKO colon cancer cell cells, the activation of endogenous p53 and exogenous p53 did not impact VEGF mRNA levels. However, studies have proposed that wild-type p53 inhibits VEGF transcription in vitro (18). p53 acts via specific regulatory protein 1 and v-src sarcoma viral oncogene homolog kinase to achieve its inhibitory effect on VEGF, thus influencing the formation of blood vessels (17-19). Although a cross-talk between p53 and VEGF has been suggested, the underlying mechanisms remain to be fully elucidated.

Gene therapy has received increased attention however, due to the complexity of tumors, single gene treatment strategies are not optional. Therefore, in the present study, a co-expression plasmid for double gene therapy in tumor cells was investigated. Wild-type p53 and VEGF short-interfering RNA (si-VEGF) plasmids were used alone and in combination in MDA-MB-231 cells, with the effects and underlying mechanisms investigated. 


\section{Materials and methods}

Cell culture and plasmids. MDA-MB-231 breast cancer cells (Chinese Academy of Sciences Cell Bank, Shanghai, China) were cultured in Dulbecco's modified Eagle's medium with $10 \%(\mathrm{v} / \mathrm{v})$ fetal bovine serum (FBS; GE Healthcare Life Sciences, Logan, UT, USA) in $95 \%$ air and $5 \% \mathrm{CO}_{2}$ at $37^{\circ} \mathrm{C}$. The eukaryotic expression vectors (Jilin University, Jilin, China) pcDNA3.1-p53 (p53), pGCsiRNA-VEGF (si-VEGF), pcDNA3.1-p53/U6 siRNA-VEGF (Pvp53) and pGCsiRNA-scramble (si-scramble; scramble siRNA sequence as a negative control) were used in these experiments. The MDA-MB-231 cells were plated into 24-well culture plates $\left(4 \times 10^{4}\right.$ cells/well). Plasmids were then transfected into cells using Lipofectamine ${ }^{\circledR} 2000$ (Invitrogen; Thermo Fisher Scientific, Inc., Waltham, MA, USA). After $48 \mathrm{~h}$, the cell morphology of all groups was observed using light microscopy (Oympus BX41-PHD-P11; Olympus Corporation, Tokyo, Japan).

3-(4,5-dimethylthiazol-2-yl)-2,5-diphenyltetrazolium bromide (MTT) assays. Transfected MDA-MB-231 cells were plated into 96 -well flat bottom microplates $\left(8 \times 10^{3}\right.$ cells/well). At 24, 48 and 72 h, MTT (5 mg/ml; Sangon Biotech Co., Ltd., Shanghai, China) was added to each well and the cells were incubated at $37^{\circ} \mathrm{C}$ for $4 \mathrm{~h}$. The medium was then removed and $200 \mu \mathrm{l}$ dimethyl sulfoxide (Sangon Biotech Co., Ltd.) was added to dissolve the reduced formazan product. The plates were read in an enzyme-linked immunosorbent assay reader (Bio-Rad Laboratories, Inc., Hercules, CA, USA) at $490 \mathrm{~nm}$. The proliferation inhibition rate was calculated according to the absorbance values.

Scratch wound assay. A scratch wound was made by scraping the monolayer of transfected cells across the cover glass with a sterile cell lifter (3008; Corning, Inc., Corning, NY, USA). Following wounding, the culture medium supplemented with $10 \%$ FBS was replaced with culture medium supplemented with $2 \%$ FBS, in order to maintain cell survival but prevent proliferation. Cells were then allowed to migrate for $48 \mathrm{~h}$. Cell migration was evaluated by measuring the size of the scratch-wound $48 \mathrm{~h}$ following wounding using an Oympus BX41-PHD-P11 microscope.

Flow cytometric analysis (FCM). Transfected MDA-MB-231 cells were washed three times with phosphate-buffered saline (Sangon Biotech Co., Ltd.). The cells were resuspended in $400 \mu$ l DNA binding buffer (Beckman Coulter Inc., Brea, CA, USA). Subsequently, $5 \mu \mathrm{l}$ annexin V fluorescein isothiocyanate and $10 \mu 1$ propidium iodide (Beckman Coulter Inc.) were added and the samples were incubated for $15 \mathrm{~min}$ and $10 \mathrm{~min}$ at room temperature in the dark, respectively. The apoptotic rate was measured by FCM using an Epics-XL-MCL flow cytometer (Beckman Coulter, Inc.).

Reverse transcription-polymerase chain reaction (RT-PCR). For RT-PCR analysis, total RNA from cells was extracted using Invitrogen TRIzol reagent (Thermo Fisher Scientific, Inc.). A total of $5 \mu \mathrm{g}$ total RNA (purified following DNase I treatment; Thermo Fisher Scientific, Inc.) from each sample was reverse transcribed to complementary cDNA using SMART ${ }^{\circledR}$ MMLV Reverse Transcriptase kit (cat. no. 639523; Takara Bio, Inc., Otsu, Japan). The resultant cDNAs (100 ng) were used in the PCR with the gene-specific primers of interest (Table I). PCR was conducted using 2X EasyTaq PCR SuperMix (cat. no. AS111-02; Beijing Transgen Biotech Co., Ltd., Beijing, China). The reaction conditions are shown in Table II. Primer concentrations for each gene were obtained by performing a series of pre-experiments. PCR products were separated by agarose gel (Invitrogen; Thermo Fisher Scientific, Inc.) electrophoresis and visualized by ethidium bromide staining.

Western blot analysis. Cells were harvested and lysed with lysis buffer (Takara Bio, Inc.). Following centrifugation at $12,000 \mathrm{x} \mathrm{g}$ for $20 \mathrm{~min}$ at $4^{\circ} \mathrm{C}$, the protein content of the supernatants was determined using Bradford reagent (Bio-Rad Laboratories, Inc.). A total of $30 \mu \mathrm{g}$ protein from each sample was separated by $12 \%$ polyacrylamide gel (Sangon Biotech Co., Ltd.) electrophoresis and transferred to polyvinylidene fluoride membranes (Invitrogen) as described previously $(3,4)$. The following antibodies were used for western blot analysis: Rabbit polyclonal anti- $\beta$-actin (1:3,000; cat. no. AP0060), rabbit polyclonal anti-p21 (1:500; cat. no. BS1269), rabbit polyclonal anti-Bax (1:500; cat. no. BS2538), rabbit polyclonal anti-Bcl-2 (1:500; cat. no. BS1511) and rabbit polyclonal anti-p53 (1:500; cat. no. BS1273); Bioworld Technology, Inc., St. Louis Park, MN, USA), rabbit polyclonal cleaved caspase-3 (1:1,000; cat. no. 9661; Cell Signaling Technology, Inc., Danvers, MA, USA), rabbit polyclonal anti-caspase 8 (1:200; cat. no. sc-7890) and rabbit polyclonal anti-cleaved caspase-8 (1:200; cat. no. sc-7890) Santa Cruz Biotechnology, Inc., Dallas, TX, USA), rabbit polyclonal anti-VEGF (1:1,000; cat. no. 19003-1-AP; ProteinTech Group, Inc., Chicago, IL, USA), mouse monoclonal anti-matrix metalloproteinase-2 (MMP-2; 1:200; cat. no. sc-13594; Santa Cruz Biotechnology, Inc.), mouse monoclonal anti-MMP-9 (1:200; cat. no. sc-21733) and anti-rabbit (1:1,000; cat. no. sc-2054) and anti-mouse (1:1,000; cat. no. sc-2005) IgG (Santa Cruz Biotechnology, Inc.). Proteins were detected using an enhanced chemiluminescence kit (cat. no. 120702-74; Advansta, Inc., Menio Park, CA, USA).

Statistical analysis. Data are presented as the mean \pm standard deviation. Statistical comparisons of data were performed using analysis of variance to determine statistical significance. Statistical analyses were conducted using SPSS 11.0 (SPSS, Inc., Chicago, IL, USA). $\mathrm{P}<0.05$ was considered to indicate a statistically significant difference.

\section{Results}

p53 and VEGF gene and protein expression in MDA-MB-231 cells transfected with the Pvp53 co-expression plasmid. The expression of the p53 and VEGF genes and proteins in MDA-MB-231 cells transfected with Pvp53 plasmid for $48 \mathrm{~h}$ was examined by RT-PCR and western blot analysis. p53 mRNA expression was significantly increased in cells transfected with p53 alone and Pvp53, whilst VEGF mRNA expression was reduced in cells transfected with si-VEGF and Pvp53 plasmids. In addition, VEGF mRNA expression in Pvp53-transfected cells was reduced compared with the 
Table I. Primer sequences for reverse transcription-polymerase chain reaction.

\begin{tabular}{lll}
\hline Gene & \multicolumn{1}{c}{ Forward primer sequence } & \multicolumn{1}{c}{ Reverse primer sequence } \\
\hline GAPDH & 5'-GGGTGATGCTGGTGCTGAGTATGT-3' & 5'-AAGAATGGGAGTTGCTGTTGAAGTC-3' \\
p53 & 5'-CCTCCTCAGCATCTTATCCG-3' & 5'-CACAAACACGCACCTCAAA-3' \\
VEGF & 5'-GAGGGCAGAATCATCACGAA-3' & 5'-GGCTCCAGGGCATTAGACA-3' \\
Bcl-2 & 5'-GACTTCGCCGAGATGTCCAGC-3' & 5'-TGTGGCCCAGATAGGCACCC-3' \\
Bax & 5'-GGCCCACCAGCTCTGAGCAGA-3' & 5'-GCCACGTGGGGGTCCCAAAGT-3'
\end{tabular}

GAPDH, glyceraldehyde 3-phosphate dehydrogenase; VEGF, vascular endothelial growth factor.

Table II. Polymerase chain reaction thermocycling conditions.

\begin{tabular}{lllll}
\hline Gene & Denaturation & Annealing & Extension & Cycle no. \\
\hline GAPDH & $94^{\circ} \mathrm{C} 30 \mathrm{sec}$ & $56^{\circ} \mathrm{C}, 45 \mathrm{sec}$ & $72^{\circ} \mathrm{C}, 45 \mathrm{sec}$ & 25 \\
p53 & $94^{\circ} \mathrm{C} 30 \mathrm{sec}$ & $56^{\circ} \mathrm{C}, 45 \mathrm{sec}$ & $72^{\circ} \mathrm{C}, 45 \mathrm{sec}$ & 28 \\
VEGF & $94^{\circ} \mathrm{C} 30 \mathrm{sec}$ & $55^{\circ} \mathrm{C}, 30 \mathrm{sec}$ & $72^{\circ} \mathrm{C}, 30 \mathrm{sec}$ & 30 \\
Bcl-2 & $94^{\circ} \mathrm{C} 30 \mathrm{sec}$ & $60^{\circ} \mathrm{C}, 45 \mathrm{sec}$ & $72^{\circ} \mathrm{C}, 45 \mathrm{sec}$ & 30 \\
Bax & $94^{\circ} \mathrm{C} 30 \mathrm{sec}$ & $56^{\circ} \mathrm{C}, 45 \mathrm{sec}$ & $72^{\circ} \mathrm{C}, 45 \mathrm{sec}$ & 30 \\
\hline
\end{tabular}

GAPDH, glyceraldehyde 3-phosphate dehydrogenase; VEGF, vascular endothelial growth factor.

si-VEGF plasmid alone (Fig. 1A and B). This result suggests that p53 is able to inhibit the expression of VEGF and is consistent with previous studies (18). The western blot results of p53 and VEGF expression were consistent with the mRNA results (Fig. 1C and D). To examine p53 function, the protein expression of $\mathrm{p} 21$ was measured. The protein expression of p21 was increased in cells transfected with p53 and Pvp53 plasmids, however was not altered in cells treated with the si-VEGF plasmid (Fig. 1C and D).

Cell morphology and survival in Pvp53-transfected cells. The cell morphology of transfected cells was investigated using light microscopy. Compared with the control, $48 \mathrm{~h}$ following transfection, the cells of the three transfection groups (p53, si-VEGF and Pvp53) were observed to be rounded, with an irregular shape and exhibiting refractive index variation. The alterations were greatest in cells transfected with the Pvp53 plasmid (Fig. 1E). The MTT assay indicated that all three plasmids inhibited the growth of MDA-MB-231 cells and the survival rate of the cells was reduced in a time-dependent manner. The Pvp53 plasmid exerted the greatest inhibitory effect on cell survival (Fig. 1F, Table III).

Effects of Pvp53 co-expression plasmid on wound-induced migration of MDA-MB-231 cells. To examine cell motility, a scratch-wound assay was used. A scratch was introduced into the confluent monolayer, and the movement of cells into the injured area was monitored by microscopy (Fig. 2A). A significant reduction in the motility of the cells in the Pvp53 group was observed at $48 \mathrm{~h}$ compared with the p53 and si-VEGF groups.

To investigate the mechanisms involved in the inhibition of motility following transfection, the protein expression levels of MMP-2 and MMP-9 were measured. The three transfection groups exhibited reduced levels of MMP-2 and MMP-9, however Pvp53 demonstrated the greatest reduction in MMP2 and MMP-9 expression levels (Fig. 2B and C).

Effects of Pvp53 on cell apoptosis and associatedmechanisms. To evaluate apoptosis in MDA-MB-231 cells transfected with Pvp53, cell apoptosis was measured by FCM. The right upper quadrant indicates late apoptosis, and the right lower quadrant indicates early apoptosis. Early apoptosis and late apoptosis were used to define the apoptotic rate. Quantitative analysis using FCM demonstrated the apoptotic rate of the control and si-scramble groups were $1.6 \%$ and $1.8 \%$, respectively. The apoptotic rate of the si-VEGF group, p53 group and Pvp53 group were $14.9 \%, 19.3 \%$ and $24.0 \%$, respectively. Compared with the control group and si-Scramble group, the apoptotic rates of the si-VEGF, p53 and Pvp53 groups significantly increased, and the highest apoptotic rates were observed in the Pvp53 group (Fig. 3A).

To determine the potential mechanisms underpinning the inhibition of cell growth, the expression levels of apoptosis-associated proteins were examined. Plasmid transfections resulted in a significant increase in the expression levels of Bax, cleaved caspase- 3 and 8 and Bax, and in addition reduced expression of Bcl-2 was observed (Fig. 3B-F).

\section{Discussion}

Maintenance of homeostasis is an essential process for cell survival. Cells are required to respond to an ever-changing environment to maintain homeostasis, and the tumor suppressor p53 is a vital component in the response to stressors such as DNA damage, oncogene activity and hypoxia (20). 
A

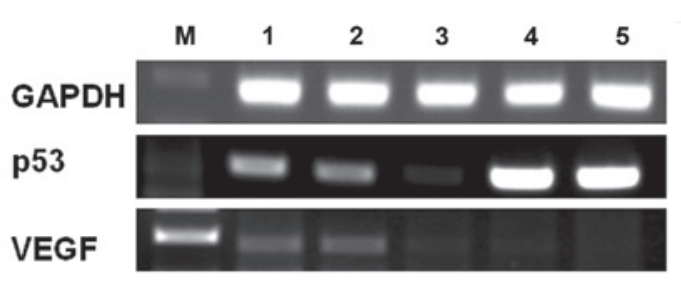

C

$\mathbf{E}$

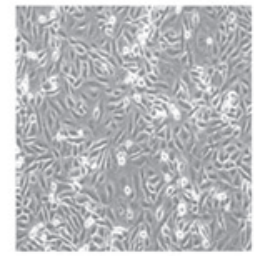

Control

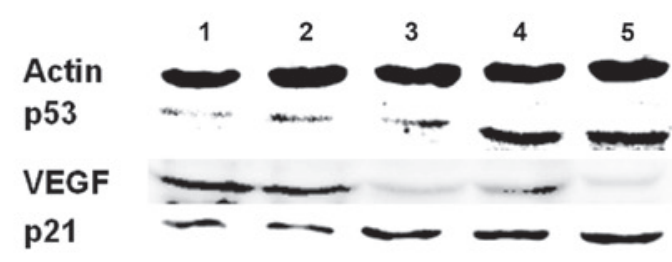

p21
B
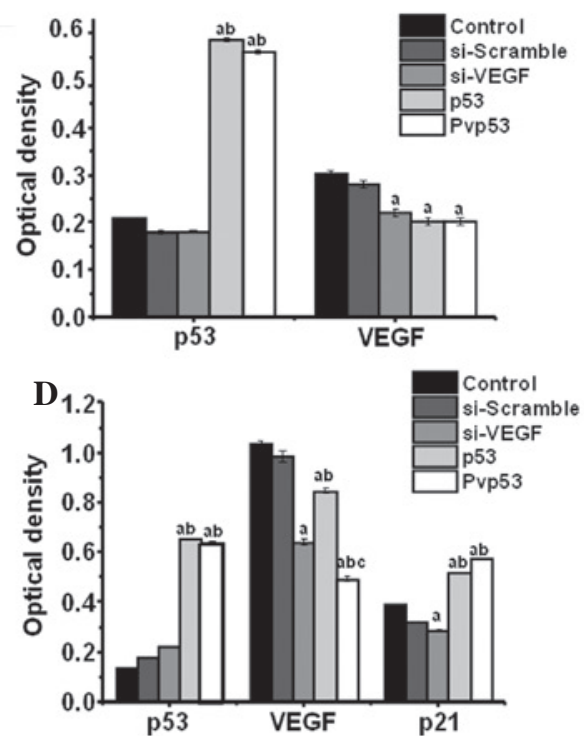

p53

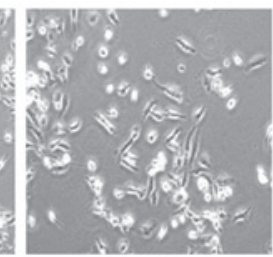

Pvp53

$\mathbf{F}$

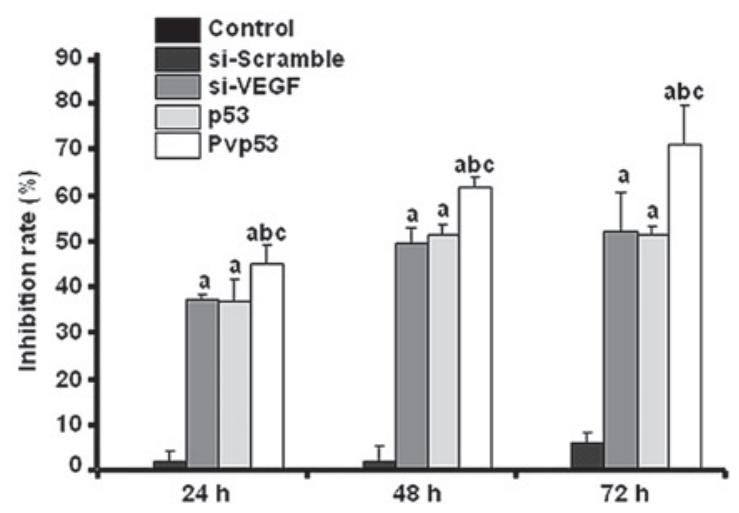

Figure 1. Effects on cell morphology and survival by Pvp53 transfection. (A and B) Expression of p53 and VEGF mRNA was measured using reverse transcription-polymerase chain reaction. (C and D) Protein expression levels of p53 and VEGF were measured by western blotting. M, marker; lane 1, control; lane 2, si-scramble; lane 3, si-VEGF; lane 4, p53; lane 5, Pvp53. (E) Images of cell morphology (magnification, x200). (F) Inhibitory rate on cell proliferation at different time points. Data are presented as the mean \pm standard deviation obtained from three independent experiments. ${ }^{a} \mathrm{P}<0.05 \mathrm{vs}$. control or si-scramble group; ${ }^{\mathrm{b}} \mathrm{P}<0.05$ vs. si-VEGF group; ${ }^{\mathrm{C}} \mathrm{P}<0.05$ vs. 553 group. VEGF, vascular endothelial growth factor; si, short interfering RNA; GAPDH, glyceraldehyde 3-phosphate dehydrogenase.

p53 and VEGF serve important roles in tumorigenesis. Previous studies have confirmed an association between p53 and VEGF, with p53 serving a role in the regulation of VEGF $(16,21,22)$. In the current study, the Pvp53 plasmid was constructed to silence the expression of VEGF, while inducing high expression levels of wild-type p53. In the p53 plasmid group, expression of VEGF was reduced, and compared with the si-VEGF plasmid, the VEGF silencing phenomenon was more overt in the Pvp53 group (Fig. 1A-D). This indicates that p53 is able to inhibit expression of VEGF, which is consistent with the observations of Farhang Ghahremani et al (18).
The tumor suppressor gene p53, termed the "guardian of the genome", serves an essential role in preserving genomic stability by preventing genome mutations (23). The major function of p53 involves the blockage of cell cycle progression in response to DNA damage (24), however the majority of tumors possess p53 mutations (13). Breast tumors with p53 mutations are predominantly classified into basal-like or the HER2-amplified subgroup, while the luminal subgroup of breast cancers almost exclusively expresses wild-type p53 (13). Typically, mutant p53 is stably expressed and accumulates in cells, with mutations in p53 able to alter the function of 
Table III. Inhibitory rate of cell proliferation.

Time (h)

\begin{tabular}{lccc}
\cline { 2 - 3 } Group & 24 & 48 & 72 \\
\hline Control & $0.0 \pm 0.0$ & $0.0 \pm 1.5$ & $0.0 \pm 3.0$ \\
si-scramble & $1.6 \pm 2.3$ & $1.7 \pm 4.7$ & $5.8 \pm 2.4$ \\
si-VEGF & $24.3 \pm 1.0^{\mathrm{a}}$ & $39.7 \pm 3.1^{\mathrm{a}}$ & $42.4 \pm 8.5^{\mathrm{a}}$ \\
p53 & $23.7 \pm 5.1^{\mathrm{a}}$ & $41.6 \pm 2.5^{\mathrm{a}}$ & $40.2 \pm 3.4^{\mathrm{a}}$ \\
Pvp53 & $31.8 \pm 4.3^{\mathrm{a}, \mathrm{b}, \mathrm{c}}$ & $52.0 \pm 2.4^{\mathrm{a}, \mathrm{b}, \mathrm{c}}$ & $63.9 \pm 4.1^{\mathrm{a}, \mathrm{b}, \mathrm{c}}$
\end{tabular}

${ }^{a} \mathrm{P}<0.05$ vs. control or si-scramble; ${ }^{\mathrm{b}} \mathrm{P}<0.05$ vs. si-VEGF; ${ }^{\mathrm{P}} \mathrm{P}<0.05$ vs. p53. VEGF, vascular endothelial growth factor; si, short interfering RNA; VEGF, vascular endothelial growth factor.

$\mathbf{A}$
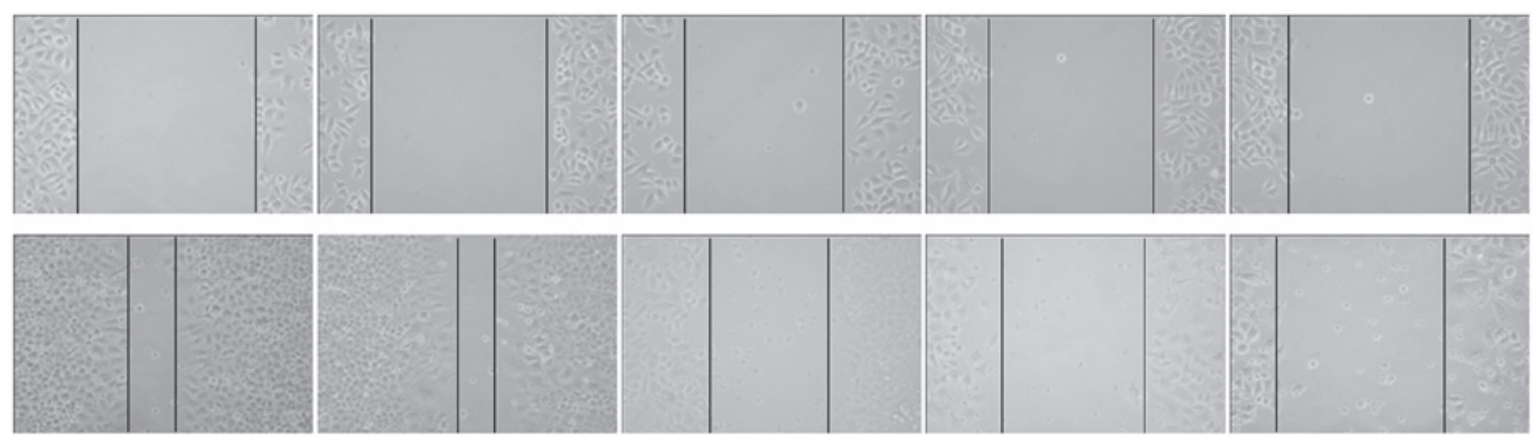

Control

si-Scramble

si-VEGF

p53

Pvp53

B

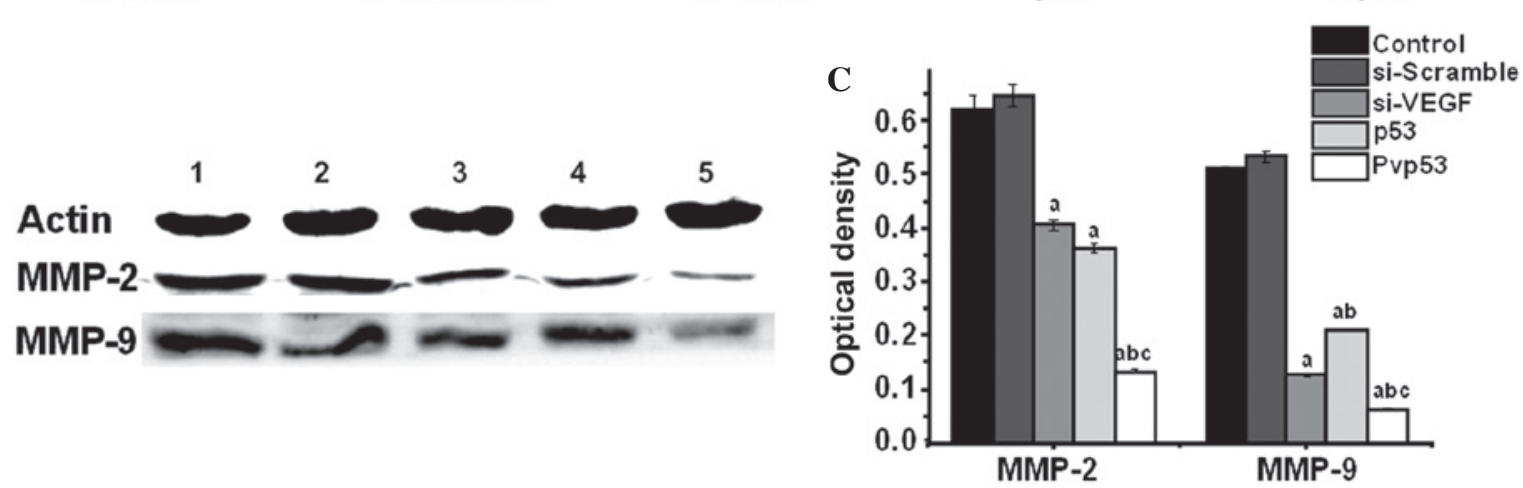

Figure 2. Effects of Pvp53 transfection on the wound-induced migration of MDA-MB-231 cells. (A) Scratch-wound assay. (B and C) Protein expression levels of MMP-2 and MMP-9 were measured by western blotting. Lane 1, control; lane 2, si-scramble; lane 3, si-VEGF; lane 4, p53; lane 5, Pvp53. ${ }^{\mathrm{a}} \mathrm{P}<0.05$ vs. control or si-scramble group; ${ }^{\mathrm{b}} \mathrm{P}<0.05$ vs. si-VEGF group; ${ }^{\mathrm{C}} \mathrm{P}<0.05$ vs. 533 group. MMP, matrix metalloproteinase; si, short interfering RNA; VEGF, vascular endothelial growth factor.

the p53 protein, and some mutations resulting in oncogenic activity (20). Previous studies have demonstrated that mutant p53 has the potential ability to induce tumorigenesis, predominantly through the inhibition of transcription, which inactivates additional tumor-suppressor genes (25-28). Mutations in p53 are diverse and alter the core molecular pathways involved in drug responses (29). Types of p53 mutations, widely termed gain of function mutations, convert the protein from a tumor suppressor to an oncogene (20).

The 553 protein is a multifunctional protein that is able to induce DNA damage and apoptosis, and has an important role in controlling cellular responses to numerous stress signals (30). p53 is post-translationally modified and degraded by proteases, and is normally expressed at low levels and is unable to bind specifically to DNA (30). Under conditions of stress, p53 accumulates via multiple mechanisms, including enhanced translation, reduced proteolytic degradation and post-translational modification (30). p53 activates the expression of pro-apoptotic proteins by transcriptional regulation, and indirectly acts on the mitochondrial pathway to induce apoptosis (31). Furthermore, p53 additionally promotes apoptosis by activating pro-apoptotic proteins (Bax, Bak) in a transcription-dependent manner, by binding to apoptosis-inhibiting proteins (Bcl-2, Bcl-XL) or by acting directly on the outer mitochondrial membrane, resulting 
$\mathbf{A}$

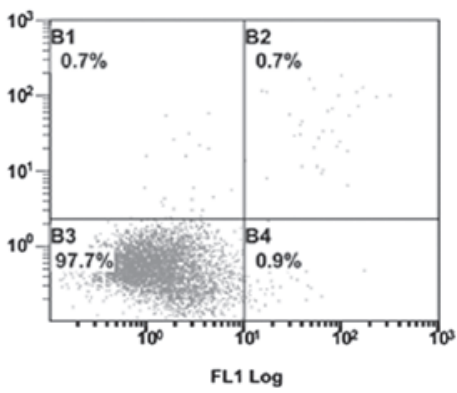

Control

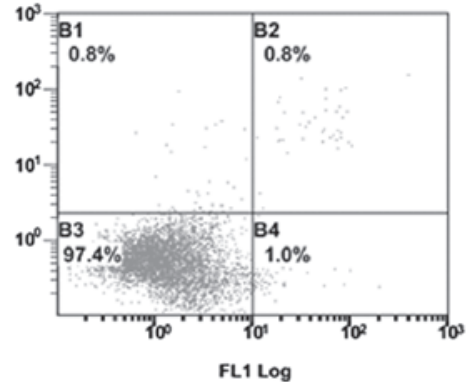

si-Scramble

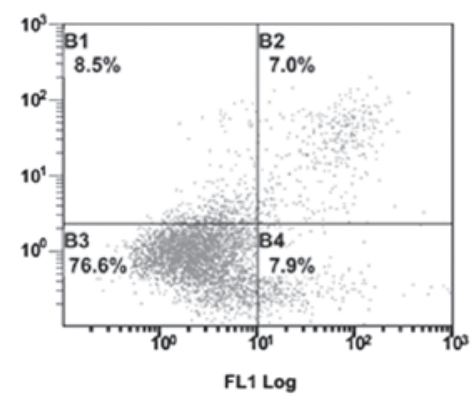

si-VEGF

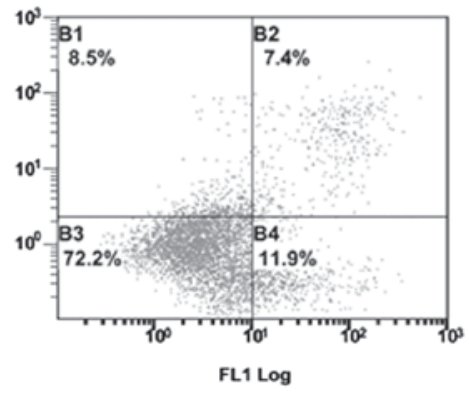

p53

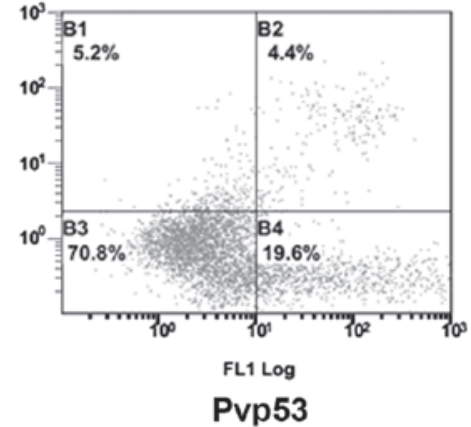

Pvp53

B

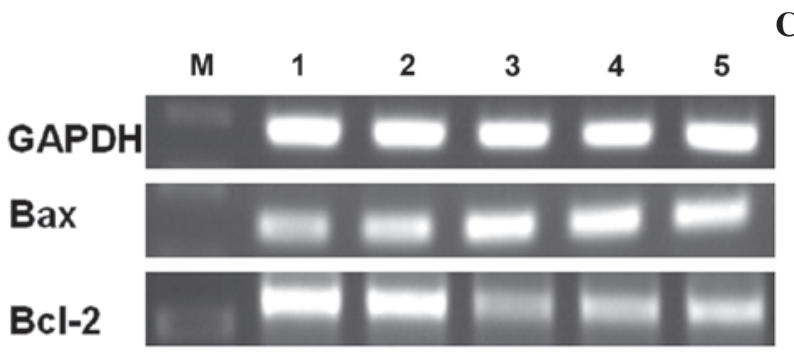

C

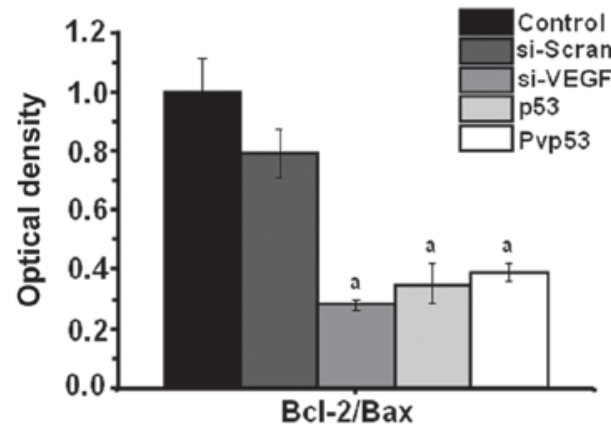

D

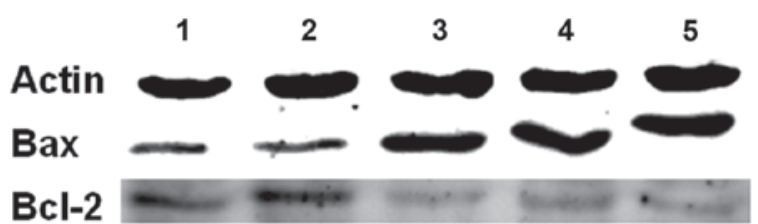

E

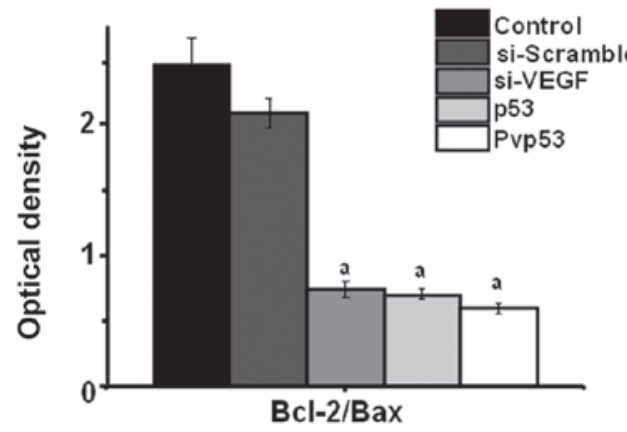

F

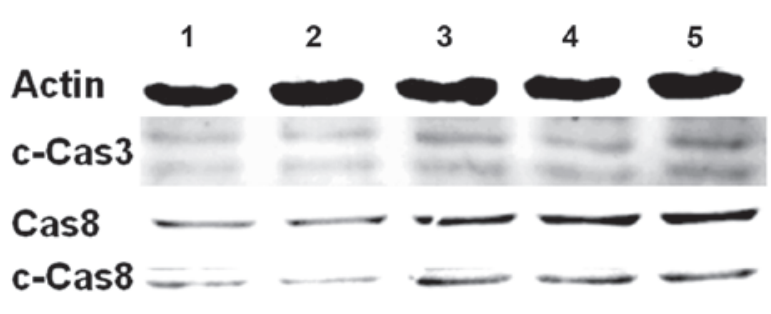

G

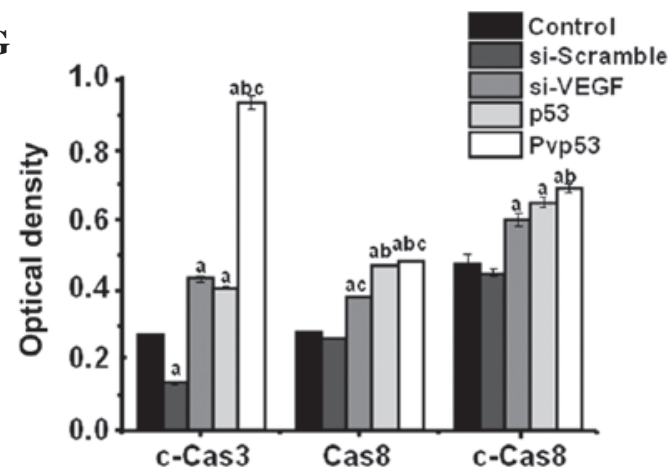

Figure 3. Effects of Pvp53 transfection on cell apoptosis. (A) Flow cytometric analysis of apoptotic cells using annexin V-fluorescein isothiocyanate and propidium iodide staining at $48 \mathrm{~h}$ following transfection. (B and C) Expression levels of Bcl-2/Bax mRNA were measured using reverse transcription-polymerase chain reaction. Protein expression levels of (D and E) Bcl-2/Bax, (F and G) Cas8, c-Cas8 and c-Cas3 were measured using western blotting. M, marker; lane 1, control; lane 2, si-scramble; lane 3, si-VEGF; lane 4, p53; lane 5, Pvp53. ${ }^{\mathrm{P}} \mathrm{P}<0.05$ vs. control or si-scramble group; ${ }^{\mathrm{P}} \mathrm{P}<0.05 \mathrm{vs}$. si-VEGF group; ${ }^{\mathrm{c}} \mathrm{P}<0.05$ vs. p53 group. si, short interfering RNA; VEGF, vascular endothelial growth factor; GAPDH, glyceraldehyde 3-phosphate dehydrogenase; Cas, caspase; c-Cas, cleaved-Cas. 
in permeability alterations and promoting apoptosis (31). The current study indicated that compared with p53 and si-VEGF single plasmid transfections, the Pvp53 co-expression plasmid significantly reduced the ratio of $\mathrm{Bcl}-2 / \mathrm{Bax}$, and increased the expression of cleaved caspase-3 and 8 , thereby promoting breast cancer cell apoptosis (Fig. 3). This result suggests that Pvp53 is able to activate the caspase pathway, indicating a pro-apoptotic function.

One of the hallmark cancer cell phenotypic alterations is angiogenesis. Tumor growth and metastasis is dependent upon the formation of new blood vessels, and tumor-derived VEGF serves an important role in the formation of new blood vessels (32-34). Numerous studies (35-37) have demonstrated that high expression of VEGF is observed in almost all malignant tumors, however normal tissues do not express VEGF or express only minimal levels. In addition, previous studies have demonstrated an association between the expression of VEGF and gastric carcinogenesis, development and prognosis (38-40). VEGF is able to induce the proliferation of endothelial cells, enhance vascular permeability and alter the state of the extracellular matrix in addition to the expression of genes (13). Studies have indicated that wild-type p53 is able to inhibit VEGF expression, tumor growth and metastasis $(13,41,42)$. Mutant p53 increases the expression of VEGF, thereby promoting tumor angiogenesis, growth and metastasis (43). p53 is able to transactivate pro-apoptotic and cell cycle arresting genes (44). The p53 downstream gene, $\mathrm{p} 21$, is a universal inhibitor of cyclin-dependent kinases (CDK), and belongs to the CIP/KIP family of CDK inhibitors (45). Furthermore, p21 possess additional functions, such as inducing apoptosis or enhancing the apoptotic response to chemotherapeutic agents (46-48). In addition, p21 is a inhibitor of VEGF and angiogenesis (16). In the current study, compared with the si-VEGF plasmid group, the p53 plasmid group exhibited downregulation of VEGF expression, indicating that p53 has a suppressive effect on VEGF, which may be associated with the high expression of p21 (Fig. 1C and D). These results demonstrate that p53 has a role in the regulation of VEGF expression, and thus part of its antitumor effect may be achieved by inhibiting the expression of VEGF.

To investigate the effect and mechanism of the Pvp53 plasmid on tumor cells, the alterations in cell migration were investigated. In a variety of tumor cells that highly express MMPs, it has been observed that the basement membrane is degraded and that certain growth factors involved in tumor development are activated (31). In the current study, the scratch-wound assay indicated that Pvp53 significantly inhibited the migration of MDA-MB-231 cells. Compared with the si-VEGF and p53 single gene transfection group, the Pvp53 co-expression group markedly affected the expression of MMP-2 and MMP-9 (Fig. 2). These results indicate that p53 and VEGF are able to regulate the expression of MMPs. In addition, Pvp53 is able to inhibit the migration of MDA-MB-231 cells by inhibiting the expression of MMP-2 and MMP-9, with the expression of MMPs being inversely proportional to the expression of $\mathrm{p} 53$, which was directly proportional to VEGF.

In conclusion, compared with the single gene approaches, the Pvp53 co-expression plasmid exhibited an enhanced inhibitory effect on the proliferation and migration of MDA-MB-231 cells, and possessed greater pro-apoptotic ability.

\section{Acknowledgements}

The current study was supported by a Research Fund for the Scientific and Technological Development Plan Project in Jilin Province (grant no. 20150414025GH) and the Scientific and Technological Research Planning Project of Education in Jilin Province [grant no. (2014)B030].

\section{References}

1. DeNardo DG and Coussens LM: Inflammation and breast cancer. Balancing immune response: Crosstalk between adaptive and innate immune cells during breast cancer progression. Breast Cancer Res 9: 212, 2007.

2. Jemal A, Bray F, Center MM, Ferlay J, Ward E and Forman D: Global cancer statistics. CA Cancer J Clin 61: 69-90, 2011.

3. Khan TM, Leong JP, Ming LC and Khan AH: Association of knowledge and cultural perceptions of Malaysian women with delay in diagnosis and treatment of breast cancer: A systematic review. Asian Pac J Cancer Prev 16: 5349-5357, 2015.

4. Ramdzan ZM and Nepveu A: CUX1, a haploinsufficient tumour suppressor gene overexpressed in advanced cancers. Nat Rev Cancer 14: 673-682, 2014.

5. Wang K, Zhang Q, Li D, Ching K, Zhang C, Zheng X, Ozeck M, Shi S, Li X, Wang H, Rejto P, et al: PEST domain mutations in Notch receptors comprise an oncogenic driver segment in triplenegative breast cancer sensitive to a $\gamma$-secretase inhibitor. Clin Cancer Res 21: 1487-1496, 2015.

6. Gurpinar E and Vousden KH: Hitting cancers' weak spots: Vulnerabilities imposed by p53 mutation. Trends Cell Biol 25: 486-495, 2015.

7. Desmoulière $\mathrm{A}$, Guyot $\mathrm{C}$ and Gabbiani $\mathrm{G}$ : The stroma reaction myofibroblast: A key player in the control of tumor cell behavior. Int J Dev Biol 48: 509-517, 2004.

8. Siemann DW and Horsman MR: Modulation of the tumor vasculature and oxygenation to improve therapy. Pharmacol Ther 153: 107-124, 2015.

9. Sia D, Alsinet C, Newell $P$ and Villanueva A: VEGF signaling in cancer treatment. Curr Pharm Des 20: 2834-2842, 2014

10. Ji K, Wang B, Shao YT, Zhang L, Liu YN, Shao C, Li XJ, Li X, $\mathrm{Hu}$ JD, Zhao XJ, et al: Synergistic suppression of prostatic cancer cells by coexpression of both murine double minute 2 small interfering RNA and wild-type p53 gene in vitro and in vivo. J Pharmacol Exp Ther 338: 173-183, 2011.

11. Zhang L, Gao L, Li Y, Lin G, Shao Y, Ji K, Yu H, Hu J, Kalvakolanu DV, Kopecko DJ, et al: Effects of plasmid-based Stat3-specific short hairpin RNA and GRIM-19 on PC-3M tumor cell growth. Clin Cancer Res 14: 559-568, 2008.

12. Moreira IS, Fernandes PA and Ramos MJ: Vascular endothelial growth factor (VEGF) inhibition--a critical review. Anticancer Agents Med Chem 7: 223-245, 2007.

13. Poon RT, Fan ST and Wong J: Clinical implications of circulating angiogenic factors in cancer patients. J Clin Oncol 19: 1207-1225, 2001.

14. Muller PA and Vousden KH: Mutant p53 in cancer: New functions and therapeutic opportunities. Cancer Cell 25: 304-317, 2014.

15. Kandoth C, McLellan MD, Vandin F, Ye K, Niu B, Lu C, Xie M, Zhang Q, McMichael JF, Wyczalkowski MA, et al: Mutational landscape and significance across 12 major cancer types. Nature 502: 333-339, 2013.

16. Mukhopadhyay D, Tsiokas L and Sukhatme VP: Wild-type p53 and v-Src exert opposing influences on human vascular endothelial growth factor gene expression. Cancer Res 55: 6161-6165, 1995.

17. Agani F, Kirsch DG, Friedman SL, Kastan MB and Semenza GL: p53 does not repress hypoxia-induced transcription of the vascular endothelial growth factor gene. Cancer Res 57: 4474-4477, 1997.

18. Farhang Ghahremani M, Goossens S and Haigh JJ: The p53 family and VEGF regulation: "It's complicated"'. Cell Cycle 12: 1331-1332, 2013.

19. Oren M and Rotter V: Mutant p53 gain-of-function in cancer. Cold Spring Harb Perspect Biol 2: a001107, 2010. 
20. Brachova P, Mueting SR, Devor EJ and Leslie KK: Oncomorphic TP53 Mutations in Gynecologic Cancers Lose the Normal Protein:Protein Interactions with the microRNA Microprocessing Complex. J Cancer Ther 5: 506-516, 2014.

21. Zietz C, Rössle M, Haas C, Sendelhofert A, Hirschmann A, Stürzl M and Löhrs U: MDM-2 oncoprotein overexpression, p53 gene mutation, and VEGF up-regulation in angiosarcomas. Am J Pathol 153: 1425-1433, 1998.

22. Pal S, Datta K and Mukhopadhyay D: Central role of p53 on regulation of vascular permeability factor/vascular endothelial growth factor (VPF/VEGF) expression in mammary carcinoma. Cancer Res 61: 6952-6957, 2001.

23. Abusail MS, Dirweesh AMA, Salih RAA and Gadelkarim AH: Expression of EGFR and p53 in head and neck tumors among Sudanese patients. Asian Pac J Cancer Prev 14: 6415-6418, 2013

24. Xu CT, Zheng F, Dai X, Du JD, Liu HR, Zhao L and Li WM: Association between TP53 Arg72Pro polymorphism and hepatocellular carcinoma risk: A meta-analysis. Asian Pac J Cancer Prev 13: 4305-4309, 2012.

25. Goh AM, Coffill CR and Lane DP: The role of mutant p53 in human cancer. J Pathol 223: 116-126, 2011.

26. Muller PAJ, Vousden KH and Norman JC: p53 and its mutants in tumor cell migration and invasion. J Cell Biol 192: 209-218, 2011.

27. Brosh R and Rotter V: When mutants gain new powers: News from the mutant p53 field. Nat Rev Cancer 9: 701-713, 2009.

28. Yi YW, Kang HJ, Kim HJ, Kong Y, Brown ML and Bae I: Targeting mutant $\mathrm{p} 53$ by a SIRT1 activator YK-3-237 inhibits the proliferation of triple-negative breast cancer cells. Oncotarget 4: 984-994, 2013

29. Khoo KH, Verma CS and Lane DP: Drugging the p53 pathway: Understanding the route to clinical efficacy. Nat Rev Drug Discov 13: 217-236, 2014.

30. Song Y, Li X, Li Y, Li N, Shi X, Ding H, Zhang Y, Li X, Liu G and Wang Z: Non-esterified fatty acids activate the ROS-p38-p53/Nrf2 signaling pathway to induce bovine hepatocyte apoptosis in vitro. Apoptosis 19: 984-997, 2014.

31. Yu J, Zhang L, Hwang PM, Kinzler KW and Vogelstein B PUMA induces the rapid apoptosis of colorectal cancer cells Mol Cell 7: 673-682, 2001

32. Moens S, Goveia J, Stapor PC, Cantelmo AR and Carmeliet P: The multifaceted activity of VEGF in angiogenesis - Implications for therapy responses. Cytokine Growth Factor Rev 25: 473-482, 2014.

33. Stamati K, Priestley JV, Mudera V and Cheema U: Laminin promotes vascular network formation in $3 \mathrm{D}$ in vitro collagen scaffolds by regulating VEGF uptake. Exp Cell Res 327: 68-77, 2014.

34. Cannon JE, Upton PD, Smith JC and Morrell NW: Intersegmental vessel formation in zebrafish: Requirement for VEGF but not BMP signalling revealed by selective and non-selective BMP antagonists. Br J Pharmacol 161: 140-149, 2010.

35. Chen J, Tang D, Wang S, Li QG, Zhang JR, Li P, Lu Q, Niu G, Gao J, Ye NY and Wang DR: High expressions of galectin-1 and VEGF are associated with poor prognosis in gastric cancer patients. Tumour Biol 35: 2513-2519, 2014.
36. Zhao J, Chen L, Shu B, Tang J, Zhang L, Xie J, Qi S and Xu Y: Granulocyte/macrophage colony-stimulating factor influences angiogenesis by regulating the coordinated expression of VEGF and the Ang/Tie system. PLoS One 9: e92691, 2014.

37. Zhao D, Pan C, Sun J, Gilbert C, Drews-Elger K, Azzam DJ, Picon-Ruiz M, Kim M, Ullmer W, El-Ashry D, et al: VEGF drives cancer-initiating stem cells through VEGFR-2/Stat3 signaling to upregulate Myc and Sox2. Oncogene 34: 3107-3119, 2015.

38. Tanaka T, Ishiguro H, Kuwabara Y, Kimura M, Mitsui A, Katada T, Shiozaki M, Naganawa Y, Fujii Y and Takeyama H: Vascular endothelial growth factor C (VEGF-C) in esophageal cancer correlates with lymph node metastasis and poor patient prognosis. J Exp Clin Cancer Res 29: 83, 2010.

39. Liu H, Yang Y, Xiao J, Lv Y, Liu Y, Yang H and Zhao L: COX-2-mediated regulation of VEGF-C in association with lymphangiogenesis and lymph node metastasis in lung cancer. Anat Rec (Hoboken) 293: 1838-1846, 2010.

40. Wang TB, Wang J, Wei XQ, Wei B and Dong WG: Serum vascular endothelial growth factor-C combined with multi-detector $\mathrm{CT}$ in the preoperative diagnosis of lymph node metastasis of gastric cancer. Asia Pac J Clin Oncol 8: 180-186, 2012

41. Gu J, Tang Y, Liu Y, Guo H, Wang Y, Cai L, Li Y and Wang B: Murine double minute 2 siRNA and wild-type p53 gene therapy enhances sensitivity of the SKOV3/DDP ovarian cancer cell line to cisplatin chemotherapy in vitro and in vivo. Cancer Lett 343: 200-209, 2014.

42. Chakraborty S, Adhikary A, Mazumdar M, Mukherjee S, Bhattacharjee P, Guha D, Choudhuri T, Chattopadhyay S, Sa G, Sen A, et al: Capsaicin-induced activation of p53-SMAR1 auto-regulatory loop down-regulates VEGF in non-small cell lung cancer to restrain angiogenesis. PLoS One 9: e99743, 2014.

43. Ravi R, Mookerjee B, Bhujwalla ZM, Sutter CH, Artemov D, Zeng Q, Dillehay LE, Madan A, Semenaz GL and Bedi A: Regulation of tumor angiogenesis by $\mathrm{p} 53$-induced degradation of hypoxia-inducible factor 1alpha. Genes Dev 14: 34-44, 2000.

44. Vousden KH and Lane DP: p53 in health and disease. Nat Rev Mol Cell Biol 8: 275-283, 2007.

45. Sherr CJ and Roberts JM: Inhibitors of mammalian G1 cyclin-dependent kinases. Genes Dev 9: 1149-1163, 1995.

46. Qiao L, McKinstry R, Gupta S, Gilfor D, Windle JJ, Hylemon PB, Grant S, Fisher PB and Dent P: Cyclin kinase inhibitor p21 potentiates bile acid-induced apoptosis in hepatocytes that is dependent on p53. Hepatology 36: 39-48, 2002

47. Kondo S, Barna BP, Kondo Y, Tanaka Y, Casey G, Liu J, Morimura T, Kaakaji R, Peterson JW, Werbel B and Barnett GH: WAF1/CIP1 increases the susceptibility of p53 non-functional malignant glioma cells to cisplatin-induced apoptosis. Oncogene 13: 1279-1285, 1996.

48. Coqueret O: New roles for p21 and p27 cell-cycle inhibitors: A function for each cell compartment? Trends Cell Biol 13: 65-70, 2003. 